\title{
Life cycle resolved observation of radiative properties of mesoscale convective systems
}

Dominique Bouniol $^{1}$

5 CNRM, Université de Toulouse, Météo-France, CNRS, Toulouse, France

Rémy Roca, Thomas Fiolleau

Laboratoire d’Études en Géophysique et Océanographie Spatiales

Université de Toulouse III, CNRS, CNES, IRD, Toulouse, France

10

Patrick Raberanto

Laboratoire de Météorologie Dynamique, Palaiseau, France

Submitted to

the Journal of Applied Meteorology and Climatology

1 Corresponding author address : CNRM/GMME/TROPIC ${ }^{2}$ S, Météo-France, 42 avenue Gaspard Coriolis, 31057 Toulouse CEDEX, France.

E-mail: dominique.bouniol@meteo.fr 


\section{Abstract (250 words)}

25 The evolution of radiative properties (outgoing longwave radiation, OLR, and albedo at the top of the atmosphere) over Mesoscale Convective System (MCS) life cycle is assessed using five years of Scanner for Radiation Budget (ScaRaB) radiometer onboard the MeghaTropiques satellite merged with geostationary infrared images. The MCS life cycle is documented using a tracking algorithm. A composite approach is then implemented to

30 document the evolution of radiative properties at each life stage at the scale of the tropical belt, in continental and oceanic regions and in specific regions. Independently of the considered region the composites share similarities with a unique maximum in albedo and a unique minimum in OLR, values of which differ depending on the environment as well as the amplitude of both parameters over the life cycle. The unique precessing orbit of the Megha-

35 Tropiques satellite allows a consideration of the albedo as a function of the local time of observation showing that the magnitude of the albedo signal is mainly controlled by the solar zenithal angle.

Sensitivity tests allow the quantification of the impact of an error in radiative properties showing that even small errors lead to substantial increment on the instantaneous cloud radiative effect. All together these elements point toward the subtle balance between life cycle, cloud radiative properties and phasing within the diurnal cycle to build the atmospheric radiative budget in oceanic or continental regions. 


\section{Introduction}

Cloud feedback is a major source of uncertainty in our understanding of the climate evolution under increased greenhouse gases in the atmosphere (Bony et al. 2015). High clouds in the tropics exert a significant contribution to the overall cloud feedback (Zelinka et al., 2012). The importance of the cloudiness induced by the tropical deep convection for the radiation budget is indeed recognized for a long time because of their effect in both the

50 shortwave (SW) and longwave (LW) radiation (Webster and Stephens, 1980; Del Genio and Kovari, 2002). This cloud feedback is associated with various physical impacts ranging from stabilizing (Ramanathan and Collins, 1991), destabilizing (Hartmann, 2002; Zelinka and Hartmann, 2010) or neutral (Del Genio et al., 2005) feedbacks prompting the need for further investigations.

In the tropics, upper level cloudiness is mainly associated with mesoscale convective systems (MCS; Del Genio and Kovari 2002; Roca et al. 2017), which are an important aspect of climate sensitivity (Bony et al. 2016). On the modeling front, the representation of these MCS in CMIP-like climate models, as sub-grid scale processes, is problematic (Del Genio et al. 2012). Various research efforts have been proposed to overcome this problem and were

60 directed either towards incorporating mesoscale organization into these climate model parameterizations (Donner et al. 2001; Elsaesser et al. 2017), via super parameterization (Kooperman et al. 2016), or by turning to global cloud resolving modeling framework (Palmer and Stevens, 2019). The latter framework is designed to resolve the mesoscale convective systems. A better appreciation of the organized nature of tropical convection is

65 accompanied with a renewed perspective on the role of these clouds on climate sensitivity to different physical perturbations. For instance, in radiative convective experiments, Hohenegger and Stevens (2016) found that climate is less sensitive to imposed increase in insolation when MCS are resolved. Similarly, the identification of self-aggregation of 
convection, one form of convective organization, in idealized simulations has been promoted

70 as an interesting framework to explore the climate sensitivity to a doubling $\mathrm{CO}_{2}$ (Wing, 2019). The importance of the organization of convective cloudiness for the radiation budget arises from the strong scale dependence of the radiative properties of the tropical cloud clusters (Roca and Ramanathan, 2000; Roca et al. 2005). Organized cloud systems span a wide range of scales from 10 to $1000 \mathrm{~km}$ (Houze Jr, 2004) and the larger the cloud shield the lower the

75 associated outgoing longwave radiation (OLR) and the brighter the system (high albedo) (Del Genio and Kovari, 2002). The largest clusters are also the strongest contributors to the LW CRE (Roca et al. 2002). Analyzing deep convective cloud objects, Eitzen et al. (2009) found similar results with the larger objects having the highest albedos (lowest OLR) and corresponding to higher values in cloud optical depth, condensate water path, and low cloud 80 top temperature. Anvil cloud radiative properties are directly related to the cloud macrophysics (Vaillant de Guélis et al. 2017) and microphysics in the uppermost part of anvil clouds (Bouniol et al. 2010; Bouniol et al. 2016). The spatial area of the cloud clusters is driven by the life cycle of the MCS (Roca et al. 2017). Yet such an important aspect of the convection-induced cloudiness remains underappreciated in the above-mentioned studies on

85 climate sensitivity and high clouds in the tropics.

Numerous studies investigated the statistical relationships among the various radiation-related parameters as well as the way the environment drives these relationships but fewer studies investigated the relation to the deep convective cloud life cycle. Futyan and Del Genio (2007) focused on the West African and Eastern Atlantic climate and use GERB

90 satellite observations to reveal the dependence of the mean OLR and albedo of deep convective systems to the life cycle of the system. The system's albedo exhibits a growing and decaying pattern centered on the mature phase of the system while the OLR is characterized by an inverted pattern with the minimum OLR being associated with the mature 
phase of the system. Using ground-based radar and geostationary observations, Feng et al

95 (2011) investigated the evolution of radiative properties of MCS as a function of the diurnal cycle over the US. Their results suggested that newly formed MCS in the late afternoon are optically thicker than MCS dissipating in the morning. Using a complete set of A-Train and geostationary data and distinguishing the different MCS sub-regions (convective, stratiform and cirriform), Bouniol et al (2016) found a similar behavior as Futyan and Del Genio (2007) but additional investigation on cloud-related parameters allowed to interpret the differences in terms of convection intensity (continental versus oceanic) and subsequent microphysical properties: denser hydrometeors and higher cloud top for continental convection. Wall et al. (2018) examined the evolution of anvil cloud properties derived from geostationary measurements over the MCS life cycle. They found a decrease of cloud top pressure with time 105 and the highest albedo just before the middle of the life cycle. A modeling study under idealized settings further indicated that the life cycle eventually yields to a near neutral cloud radiative effect (Hartmann et al. 2018) involving interaction between radiative, microphysical and turbulence processes. These studies all point towards the importance of the time evolution of the macro- and microphysical properties of the storms to produce the overall near neutral

110 net radiative effects of the cloud system at the top of the atmosphere (TOA).

Here we propose to revisit the radiative properties of mesoscale convective systems in the tropics over their life cycle using satellite observations. A large observational dataset of MCS and the dedicated radiation measurements of the Scanner for Radiation Budget-3 (ScaRaB) instrument on board the Megha-Tropiques (MT) mission are used for this endeavor

115 and the whole tropical belt is documented. The MT satellite is located on a precessing orbit, allowing to include the consideration of the diurnal cycle in our analysis. The paper is structured as follows. First data and methodology for the merging of the two sets of observations are presented. The particularity of this paper is to consider the whole tropical 
belt including both summer and winter period and continental and oceanic environments.

120 Evolution of radiative properties are then documented and contrasted in various

environments. In the discussion section, impact of changes within the life cycle is assessed. A discussion and concluding remarks close the paper.

\section{Data}

\section{a. Radiation at the top of the atmosphere}

We use on the ScaRaB instrument onboard the Indo-French MT satellite (Roca et al. 2015) to document the evolution of these MCS properties throughout their life cycle and over the diurnal cycle for the whole tropical belt. The low inclination orbit at $20^{\circ}$ on the Equator, the high altitude of flights, and the relatively wide swath (about $2200 \mathrm{~km}$ ) enhance the sampling of the tropical regions, compared to typical low earth observing platforms (Roca et al. 2015). The precession cycle is responsible for the complex aliasing between the MT orbit and the diurnal cycle. This makes ScaRaB measurements the only dataset covering the whole tropics and sampling all local times for an entire year since ERBS (Rutan et al. 2014).

ScaRaB measures the total energy between 0.2 and $100 \mu \mathrm{m}$ and the SW channel $(0.2-4 \mu \mathrm{m})$ is subtracted to obtain the $\mathrm{LW}$ part of the spectrum. ScaRaB has been designed to

135 measure earth radiation components at the TOA with an accuracy below $1 \%$ (Kandel et al. 1994). The ScaRaB radiometer performs regular onboard calibration using a calibration module (Duvel et al. 2001). Cross-comparison of measured radiances as well as OLR and OSR are also regularly performed with CERES instrument onboard Terra showing that both technologies produce consistent estimates of outgoing radiation at the TOA (Trémas et al. 2015). ScaRaB on MT has a square-shaped pixel footprint of $41.6 \mathrm{~km}$ side length at nadir with pixel overlapping by $29.6 \mathrm{~km}$ in the cross-track direction and $36.6 \mathrm{~km}$ along track. The radiances are converted to hemispheric flux at the TOA after determination of the scene type 
using the additional infrared (IR) channel 10.5-12.5 $\mu \mathrm{m}$ and application of angular distribution models (ADMs). These ADMs have been built using artificial neural networks trained on CERES onboard TRMM for which all the solar zenith angles (SZA) are sampled (Viollier et al. 2009).

The ScaRaB flux estimates used in this study is the level 2B product and corresponds to the projection of the original square-shaped ground pixels of the radiometer on a $0.5^{\circ} \times 0.5^{\circ}$ regular grid considering the point spread function of the instrument (Gif et al.

150 2011). To avoid undersampling at the swath edge only viewing zenith angles lower than $50^{\circ}$ are considered in the present analysis. Since the calibration of the instrument is in very good agreement with CERES and the algorithm shares the ADM in the radiance to flux conversion, CERES and ScaRaB fluxes also agree within a few percent with each other (Roca et al. 2015; Trémas et al. 2015). The error budget of the CERES products provides a reference to discuss the error budget of the ScaRaB fluxes. The overall uncertainty of the TOA instantaneous allsky flux is about $1.8 \%$ in the LW and 3\% in the SW (Loeb et al. 2007). When only pixels overcast by upper level ice clouds are considered the budget reads between $2.3 \%$ and $4.1 \%$ for the SW and $4.6 \%$ and $5.4 \%$ for the LW. These rough estimates will serve as a baseline to interpret the sensitivity experiments detailed in Section 5.

\section{b. Morphology of Mesoscale Convective Systems}

MCS are identified and tracked by the Tracking Of Organized Convection Algorithm through a 3-D segmentatioN (TOOCAN, Fiolleau and Roca 2013a), which is applied to IR images collected by geostationary platforms distributed around the equator. This algorithm is based on an original 3-D image processing technique which aims at segmenting the high cold cloudiness delineated in the spatio-temporal domain by a 235K threshold into MCS. This 235K threshold is a good compromise to include as much anvil clouds as possible, avoiding 
the contribution of low and mid-level clouds that may develop under thinner cirrus clouds (Bouniol et al. 2016). The main skills of the TOOCAN algorithm are to overcome the traditional split and merge artifacts (Figure 1a), to track MCS from their earliest stages of initiation up to their latter stages of dissipation, and to identify MCS regardless of their degree of organization. A global tropical coverage by the geostationary satellites is achieved by using data from MSG1-2-3, HIMAWARI-8, GOES-13 and 15, METEOSAT-7 and MTSAT-2 during the 2012 to 2016 period. The IR-imagers onboard these platforms all have different spatial resolutions, spectral response functions, and calibration drifts. These data have been homogenized and intercalibrated. Inhomogeneity of the spatial resolution has been taken into account by remapping all the geostationary data to a common $0.04^{\circ}$ equal angle grid. To avoid an over-segmentation of the MCS detected by TOOCAN, the temporal resolution is aligned at 30 minutes regardless of the geostationary platform. The observed brightness temperatures are inter-calibrated, spectrally normalized and limb-darkening-corrected against the 2012-2016 observations of the ScaRaB IR channel, yielding to a residual uncertainty of the order of $2 \mathrm{~K}$ (Fiolleau et al. 2020). The TOOCAN algorithm has then been applied to this 5-year IR homogenized database, giving access to the integrated morphological parameters of each identified tropical MCS (lifetime duration, propagated distance, etc.), as well as the morphological parameters at each stage of their life cycles (cold cloud surface, average brightness temperature).

\section{Methods}

\section{a. Building life cycle-resolved composite of radiation properties}

A simple classification of MCS based on duration is used (Fiolleau and Roca 2013b). Class 1 consists of MCS lasting less than five hours and class 2 consists of longer MCS. A further separation is then applied among the class 2 systems, which are then split according to the complexity of the evolution of their cloud shield. Class 1 MCS only explain 
$2.5 \%$ of the cold cloudiness even though they are very numerous. Class 2a MCS correspond to systems that only have one growth and decay of their cloud shield surface. They explain $84 \%$ of the cold cloudiness. The class 2b MCS have a more complex evolution of their cloud shield area and they explain about $13.5 \%$ of the cold cloudiness at the tropical scale (Roca et al. 2017).

The life cycle of each individual class 2a system is then divided in 10 life stages in the following and the complete life cycle can be documented by aggregating numerous ScaRaB observations of MCS at the same life stage. This process has already been applied to the macrophysical, microphysical and radiative properties as measured by the A-Train for MCS sampled in three different geographical regions (Bouniol et al. 2016), and for radiative and microphysical properties derived from HIMAWARI observations (Wall et al. 2018).

In the present study, the pixels of the TOOCAN segmented images at a $0.04^{\circ}$ spatial resolution are collocated spatially and temporally with the ScaRaB observations at a $0.5^{\circ}$ spatial resolution. This process is illustrated in Figure 1b and Figure 1c for the OLR and the albedo (defined as the ratio of OSR to the incoming SW flux) with the MCS edges superimposed. Lower OLR values and higher albedo values are systematically found within MCS contours. The two panels of Figure 1 also highlight two other important aspects: a given $0.5^{\circ}$ grid point can be partially or totally filled by one or several MCS. A “filling” fraction $\left(\mathrm{F}_{\mathrm{f}}\right)$ is introduced and corresponds to the fraction of a $0.5^{\circ}$ ScaRaB grid point occupied by a MCS identified by TOOCAN. This filling fraction is determined by the ratio of the number of MCS pixels at a $0.04^{\circ}$ spatial resolution collocated within a $0.5^{\circ}$ grid point and the number of geostationary $0.04^{\circ}$ pixels located within a $0.5^{\circ}$ grid point. The second aspect is that the finite swath width of the ScaRaB instrument partially samples MCS located at the swath edge. The impacts of both effects on the MCS population contributing to the life cycle composite are investigated in the following. 


\section{b. Merging data with different spatial resolution}

The potential impact of the different resolutions between ScaRaB and TOOCAN output is illustrated in Figure 1c where only two $0.5^{\circ} \mathrm{ScaRaB}$ grid points (the brightest) are nearly completely enclosed within the MCS contours. These two ScaRaB grid points have high values of $F_{f}$. A relatively high albedo is found for this MCS if only high $F_{f}$ are considered to compute the averaged radiative properties at the scale of the MCS. In this case, the averaged albedo computed is not representative of the MCS albedo as the edges of the MCS are not considered. If any ScaRaB grid point that hits the MCS (hence any grid point with $\mathrm{F}_{\mathrm{f}}>$ 0 ) is included in the mean computation (dotted contour), a relatively lower value of albedo is found as grid points with a low $F_{f}$ include contribution from the MCS neighborhood, e.g., other cloud types or even clear sky. In this case the averaged value at the MCS scale is not representative of the SW flux reflected to space by this particular object. The same effect exists for OLR. To overcome this issue, a trade-off between these two pictures is needed and a $F_{\mathrm{f}}$ threshold above which, $0.5^{\circ}$ ScaRaB grid points, should be included in MCS averaged radiative properties needs to be identified.

For that purpose, we focus on MCS observed by the imager onboard MSG-2 for the 2012-2016 period. First, for each identified MCS at each life stage, the « reference » brightness temperature $\left(\mathrm{Tb}_{\mathrm{geo}}\right)$ is computed as the average of the radiance (at the $0.04^{\circ} \mathrm{IR}$ image resolution) enclosed within the MCS contour and then converted to brightness temperature. The same radiances are averaged and converted to brightness temperature in the $0.5 \mathrm{x} 0.5^{\circ} \mathrm{ScaRaB}$ grid and the corresponding $\mathrm{F}_{\mathrm{f}}$ is determined. From these lower resolution data sets the average brightness temperature is recomputed at the scale of the MCS by considering only ScaRaB grid points above a given value of $F_{f}$, noted $T b_{\text {grid. }}$. Comparing the two mean brightness temperatures allows to determine the more suitable filling threshold that keeps $\mathrm{Tb}_{\text {grid }}$ as close as possible to $\mathrm{Tb}_{\text {geo }}$. Figure 2a shows the evolution of the difference 
between these two mean brightness temperatures as a function of the MCS area for different threshold in $\mathrm{F}_{\mathrm{f}}$ (the different colors). As expected, the lower filling thresholds induce a bias that can reach $26 \mathrm{~K}$ for MCS of $210^{3} \mathrm{~km}^{2}$, which means that a large fraction of the atmosphere has either clear sky or lower clouds that contribute to $\mathrm{Tb}_{\text {grid. }}$. This difference decreases as the MCS area increases, even if it remains higher than $10 \mathrm{~K}$, because in these situations the fraction of high $\mathrm{F}_{\mathrm{f}}$ grid points increases at the expense of low $\mathrm{F}_{\mathrm{f}}$ grid points. The opposite effect is observed if $\mathrm{Tb}_{\text {grid }}$ is computed using only high $\mathrm{F}_{\mathrm{f}}$ grid points (dark red). In this case a negative bias is obtained, which means that only the coldest parts of the MCS are included in the computation of $\mathrm{Tb}_{\text {grid }}$ and a large part of the MCS edges are not included anymore.

Computing $\mathrm{Tb}_{\text {grid }}$ with $F_{f} \geqslant 70 \%$ grid points appears as a reasonable trade-off between not considering the MCS edges and not introducing a bias in the average values of $\mathrm{Tb}_{\text {grid }}$ to the colder characteristics as the differences between the two temperatures remain

255 smaller than $2 \mathrm{~K}$ (in absolute value), which corresponds to the uncertainty attached to the IR dataset of Fiolleau et al. (2020) for MCS larger than $610^{3} \mathrm{~km}^{2}$. Therefore, MCS of smaller areas cannot be accurately documented using the $0.5^{\circ} \mathrm{ScaRaB}$ observations. This critical area of $6.10^{3} \mathrm{~km}^{2}$ corresponds to an equivalent radius of $43 \mathrm{~km}$, which is a typical scale used to define MCS in Xu et al. (2005) or in Del Genio and Kovari (2002) where a MCS is defined by contiguous $85 \mathrm{GHz}$ TMI rain pixels having an equivalent radius of $25 \mathrm{~km}$. The $235 \mathrm{~K}$ envelope is largely enclosed in this raining part and the non-precipitating anvil can exceed twice this raining region. Imposing this $70 \%$ filling threshold reduces by $44 \%$ the number of class $2 \mathrm{a}$ MCS that can be used to document the life cycle with the ScaRaB data. This ratio is the same if the full tropical belt is considered. Including the critical area threshold in order to keep the difference lower than $2 \mathrm{~K}$ leads to the removal of an additional $6 \%$ of the available sample. This means that $50 \%$ of the class 2a detected MCS can be considered in the present study. 
The figure $2 \mathrm{~b}$ shows the population of MCS as a function of their area and the different filling thresholds. As expected from the earlier considerations the more numerous MCS are the ones of smallest area (lower than $100 \mathrm{~km}^{2}$ ) and considering MCS that have $\mathrm{F}_{\mathrm{f}}$ at least at $70 \%$ points toward the largest MCS. MCS are known to be smaller at the beginning and at the end of their life cycle (Roca et al. 2017). This implies that these life stages will be less sampled or sampled with a larger uncertainty in the present study, as documented in the next section.

\section{c. Impact of a finite swath width, the MT orbit, and ScaRaB data resolution on the MCS}

275 sample

Figure 3a shows the area distribution of class 2a MCS detected by TOOCAN within the five years of data without (solid lines) and with including the minimum area and filling threshold defined in the previous section (dashed line). The total distribution of class 2a MCS (bold solid black line) has its mode value about $3.210^{3} \mathrm{~km}^{2}$ with a majority of MCS having a surface between $10^{3}$ and $510^{4} \mathrm{~km}^{2}$. Imposing a minimum $\mathrm{F}_{\mathrm{f}}$ of $70 \%$ and a $610^{3} \mathrm{~km}^{2}$ minimum area automatically shifts the distribution towards wider cluster (dashed line), with a modal value that becomes $1.510^{4} \mathrm{~km}^{2}$.

MT intercept $25 \%$ of class 2a MCS at the scale of the tropical belt (corresponding in this study to all latitudes lower than $30^{\circ}$ North and South). However, this number does not

285 consider that a given fraction of these MCS may be partially sampled by the MT wide swath. The requirement of a minimum overlap between the cluster surface and the ScaRaB swath (color lines) tends to narrow the distribution around the modal value. However, in all cases the area distribution obtained using the MT orbit remains close to the distribution obtained directly from the TOOCAN data base. Based on these observations we only consider class 2a MCS that are at least $50 \%$ enclosed in ScaRaB swath. This leads to a reduction of about $10 \%$ of the MCS sample. Only considering clusters entirely sampled (dark red curve) by ScaRaB 
reduces the number of MCS by $25 \%$. In the present case we are far from the TRMM PR swath (215 km) impact as documented by Nesbitt et al. (2000) for which more than $54 \%$ of the mesoscale storm and $82 \%$ of more intense storm detected using the same definition as Kovari and Del Genio (2002) are partially sampled. The number of clusters is approximately divided by two when the filling/area threshold is considered (second number for the green $50 \%$ intercept line on Figure 3a).

The solid line in Figure 3b shows the number of class 2a MCS detected by TOOCAN. The MT sampling reduces the number of class 2a MCS detected by TOOCAN to the number shown by the dashed line in Figure 3b. Finally, applying the filling/area constraint leads to the dotted line and has the effect of undersampling the beginning and the end of the life cycle with the number of MCS reduced by an order of magnitude with respect to the dashed line. The results for these two bins are included in the following (generally shown with dashed lines) but the observational limitations should be kept in mind for analysis of the MCS life cycle.

As a summary, composite life cycles are built using MCS that are intercepted by more than $50 \%$ of the ScaRaB swath, with a horizontal extent larger than $610^{3} \mathrm{~km}^{2}$. Their averaged radiative properties are constructed by averaging ScaRaB grid points filled by more than $70 \%$ of a MCS.

\section{Analysis of radiative properties over the MCS life cycle}

In this section the evolution of radiative property over the MCS life cycle is analyzed. The evolution of the radiative property is investigated for MCS over the whole tropical belt, and in a second step for different major convective areas.

\section{a. Analysis at the tropical scale and for different environments}


A tropical mean composite of OLR and albedo as a function of the life stage is computed and shown in Figure 4a and 4b. A well-defined minimum in OLR and a maximum in albedo is observed once in the life cycle, which is a similar behavior to that found by Futyan and Del Genio (2007). The present albedo strongly differs with results from Bouniol et al. (2016) in spite of the use of the same methodology. In this earlier study, albedo values were examined separately for the different parts of the MCS, but the albedo at the scale of the whole MCS can be approximated to the albedo of the cirriform part which has the larger areal contribution to MCS anvil. In most cases, these values remain around 0.5. However, the 0.6 value found at the scale of the tropical belt is rather close to the values found in stratiform parts in Bouniol et al. (2016). For OLR the black bold line in Figure 4a may be interpreted as an area-weighted average (in particular at the beginning of the life cycle) of the OLR values found for the various parts of the MCS.

The specificity of the Bouniol et al. (2016) composites is that they were built from the A-Train data located on a sun-synchronous orbit with an equatorial crossing time of 0130 Local Time (LT). The precessing orbit of the MT satellite is able to sample all the local times 330 for each life stage and hence to further analyze the composite shown in Figure 4 (bold black line) according to the Local Solar Time (LST) of observation by MT. These LST composites are shown as color lines in Figure 4a and 4b. As expected, OLR shows a relatively low sensitivity to the LST. The variability found in Figure 4a is mainly related to the variation in temperature of the underlying surface, as documented later. The spread of albedo as a function of LST is wider, with lower albedos for 12LST compared to sunset and sunrise. These higher values at dusk or dawn are due to the apparent increase in cloud fraction with zenith angle and the higher Rayleigh scattering of radiation with increasing zenith angle (Liou 2002 ; Rutan et al. 2014). For a given life stage the spread in albedo due to solar zenith angle (which is about 0.2) is larger than the variations found within the life cycle (which are between 0.05 and 0.1 
340 for a given solar time). The green lines in Figure 4, close to the 1330LT A-Train sampling, show the same order of magnitude as in Bouniol et al. (2016). Particular attention should hence be exerted when building composites of albedo using precessing satellite observations since the resulting composite contains a signal from the MCS life cycle (changes observed along a color line in Figure 4) and microphysical property evolution on one hand and a signal from the diurnal cycle (spread among the different color lines in Figure 4) on the other hand.

Figure 4c and 4d show the distribution of MCS as a function of LST for each life stage. Even at the scale of the full tropical belt a preferred time of triggering of MCS is observed in the middle of the afternoon and MCS are the largest between 17 and 18LST (middle of the life cycle) when the sun is down, as shown on both panels 4c for OLR and 4d

350 for albedo measurements. The impact of this heterogeneous sampling will be further analyzed in the following sections.

Figure 5 shows oceanic and continental MCS statistics. An oceanic MCS is defined as a cluster that is observed over the oceanic surface but never passed over land surface. This definition therefore excludes all MCS initiated over islands that export over the oceanic

355 surface, which may artificially create a diurnal cycle of oceanic convection (Yang and Slingo 2001). The lower panel of Figure 5 shows the contrasted diurnal cycle of convection between land and sea with a preferential time of triggering between 13 and 14LST (and nearly no MCS triggering between 05 and 100LST), which imprints a very preferential LST of observation for a given life stage (Figure $5 g$ and 5h). The occurrence of MCS remains rather

360 homogeneous for the oceanic surfaces (Figure 5e and 5f), even if small preferential daytime convective life cycle seems to exist.

The effect of continental surface is clearly seen in OLR composites (Figure 5a and 5c) with a reduced spread for composite life cycle as a function of LST for oceanic MCS. Both spreads have the same order of magnitude (between 10 and $20 \mathrm{Wm}^{-2}$ and between 0 and 
$10 \mathrm{~W} \mathrm{~m}^{-2}$ respectively) as the root mean square of the first principal component of OLR calculated by Smith and Rutan (2003) attributed in their study to solar heating of the surfaceatmosphere system. For continental MCS, the OLR evolutions according to LST are split in two families: the night times, with lower values in OLR in particular at the beginning of the life cycle, and the day times with higher values in OLR. The resulting composite (bold black 370 lines in the first row in Figure 5) corresponds to the average of the colored line weighted by the fraction of MCS that occurs at each LST within a given life stage. This weighted average leads to very similar shape in OLR evolution over the MCS life cycle for both land and ocean. A well-defined minimum is observed for both about life stage 4, with just slightly lower values for continental MCS. As triggering time is relatively homogeneous over the day for oceanic areas, a part of the spread of the evolution of the radiative properties over MCS life cycle may be attributed to different evolution according to the triggering time as documented by Sokol and Hartmann (2020). More quantitatively, Wall et al. (2020), using a similar composite approach, found a difference in OLR of about $10 \mathrm{Wm}^{-2}$ for aged anvil cloud over the Western Pacific. Higher values of OLR are found for MCS triggering and developing during night but which are aged during day time.

The mean composites of albedo (Figure 5b and 5d) are different among the oceanic and the land environments with a well-defined maximum for continental MCS and a constant value followed by a decrease for oceanic MCS. This difference in shape in albedo evolution over the MCS life cycle is mainly due to the diurnal cycle of continental MCS, with an average weighted by the high sunset albedos at about the middle of the life cycle. However, after the middle of the life cycle, the albedos of oceanic MCS are systematically lower than albedos of continental MCS regardless of the LST (or the SZA). This means that some differences in microphysical properties such as higher ice water content or/and cloud optical 
depth should exist among continental and oceanic MCS during the second phase of their life cycle.

\section{b. MCS life cycle at regional scale}

Figure $6 \mathrm{~b}$ and 6c show the comparison of mean composites for three oceanic domains of Figure 6a. The evolution of albedo is on average remarkably similar within the three oceanic regions. However, albedo values are systematically higher for MCS sampled in the Atlantic Ocean (solid lines) than for MCS sampled in the Pacific ocean (dotted lines). They are themselves brighter than MCS sampled in the Indian ocean (dashed lines), when split according to SZA (for life stage 2, 5 and 8 corresponding to growing, mature and decaying phase). This holds in particular when the sun is close to zenith (about 12LST) corresponding to the lower values of albedo. The similar resulting averages (Figure 6c) are a consequence of the sampling within the diurnal cycle, in spite of very similar patterns (Figure 6d to $6 f)$.

A systematic difference exists for the Atlantic Ocean where MCS have an OLR about $5 \mathrm{Wm}^{-2}$ higher than those in the Indian and Pacific Oceans. Bouniol et al. (2016) found a lower cloud top altitude, as observed by the CALIPSO lidar, for Atlantic MCS with respect to the Indian ocean MCS by about $1 \mathrm{~km}$. A similar cloud top altitude is found in the CloudSat observations, which implies a deeper layer of thin clouds at the top of Indian ocean anvil clouds. This difference in cloud top altitude as detected by the lidar is about $500 \mathrm{~m}$ at stage 4 . Vaillant de Guèlis et al. (2017) demonstrated that the OLR is directly linked to the altitude at which the lidar signal vanishes $\left(\mathrm{T}_{\text {opaque }}\right)$ and to the cloud top detected by the lidar. They

410 showed that OLR decreases by $2 \mathrm{Wm}^{-2}$ when $\mathrm{T}_{\text {opaque }}$ decreases by $1 \mathrm{~K}$. In the present case, $\mathrm{T}_{\text {opaque }}$ can be approximated to the cloud top detected by the radar and the $5 \mathrm{Wm}^{-2}$ difference can be attributed to the 500m lower lidar cloud top altitude in the Atlantic Ocean. These 
observations demonstrate that this layer of thin clouds at the top of deep clouds has an impact on cloud emissivity. contrasted continental regions were selected: the semi-arid region of West Africa, the continental South America (including the Amazonia region) and the Maritime Continent. The latter is not properly a continental region, but rather a mix between island and surrounding ocean, and all MCS are included in the composites without any distinction. The distribution of MCS for the Maritime Continent is very similar to oceanic MCS. Interestingly a shift of about two hours in MCS triggering is observed between West Africa and South America and this shift in preferential time of occurrence persists for the rest of the life cycle.

Radiative properties have different behaviors depending the continental area considered (Figure 7b and 7c). Values in OLR differ up to stage 5, with the lowest values found in West Africa and marked deepening for MCS of South America with a decrease of 10 $\mathrm{Wm}^{-2}$ in the first half of the life cycle. Indeed, West Africa MCS reach low OLR values since the first stages of their life cycle. The evolution of MCS radiative properties over the life cycle in Maritime Continent shows the same shape and values as the other oceanic regions examined previously. After the middle of the life cycle, OLR shows a similar behavior for all the regions, with an increase of about $20 \mathrm{Wm}^{-2}$ in the decaying phase.

The life cycle resolved albedo for Maritime Continent MCS follows that of oceanic MCS. For low SZA, West African MCS are the brightest, with high albedos observed at the beginning of their life cycles. But albedo of South America MCS becomes higher at half of the life cycle to reach the values of West Africa about stage 5, followed for both regions, by a slow decrease, with the same slope, but still higher by about 0.05 than for oceanic MCS. Higher values for both continental regions with respect to ocean MCS confirm that the intense convection over land surfaces generates denser hydrometeors that are more efficient for 
scattering and reflecting solar flux in agreement with Del Genio and Kovari (2012) or Sohn et al. (2015). When examined as a function of SZA, the differences at the beginning of the life time of MCS between South America and West Africa results from different albedo properties. Values are lower for South America (dashed lines in Figure 7) compared to West Africa (solid line in Figure 7) regardless of the SZA. Sohn et al. (2015) found lower effective radius and ice water content for the whole vertical profile for South America's MCS with respect to Africa.

As a summary, regional differences in shape and magnitude of the composite life cycle resolved radiative properties are found. They are related to the convective controlling factor. For the albedo, the major influence appears to be the phasing within the diurnal cycle.

\section{Discussion}

In the previous section it was demonstrated that OLR and albedo are shaped by different parameters over the life cycle of MCS. Regarding the albedo, differences in magnitude (even split with SZA) are observed in particular between continental and oceanic areas, as well as on the regional scale. However, the SZA (or the LST) parameter seems to have the strongest influence on albedo. In order to quantify how these different parameters recombine at the scale of the life cycle, the evolution of the albedo of a «typical » MCS of a given lifetime duration for a usual triggering time can be simulated from the different composites. The different color lines in Figure 8 show the evolution of albedo over the life cycle for the different LST. Depending on the triggering time and the life duration, albedo of a typical MCS jumps from one color line to the other as depicted by the black crosses. Over continental areas, MCS are mainly triggered during the afternoon and have therefore low albedos that increase rapidly as the sun sets (Figure 6 and 7). These continental MCS reach their maximum albedo values at the middle of their life cycles, which is also the time stage when MCS reach their largest area (Roca et al. 2017). In the particular case of a system 
lasting about $10 \mathrm{~h}$, it is also a time when sun is down (Figure 8). The sensitivity to the shift in triggering time is also observed (Figure $8 \mathrm{a}$ and $8 \mathrm{~b}$ ) where the earlier triggering in South America offers a longer exposure to the sun light. Oceanic convection (Figure 8c) does not have a strong diurnal cycle (Figure 6) but is regularly observed to be triggered in the morning (Yang and Slingo 2001). Wall et al. (2020) also show that anvil clouds are more laterally expansive and more persistent when heated by the sun and hence can largely contribute to the radiative budget. This morning triggering corresponds to high values of albedos (because of large SZA) but small area. These albedo values then decrease to lower values as the sun rises. Oceanic MCS also reach their lower values in albedo after the middle of their life cycle. In spite of a relatively well distributed triggering of the convection within the diurnal cycle, the shape of the evolution of the simulated life cycles with LST in Figure 8c for the longest MCS is very similar to the shape of the mean albedo of marine convective region as a function of

475 LST of Rutan et al. (2014) (see their Figure 1). In short, the diurnal cycle of convection tends to amplify the albedo properties of continental areas and to moderate the one of oceanic areas, even if microphysical properties are identical.

A second aspect that can be explored is the sensitivity of the CRE to microphysical properties evolution over the MCS life cycle. This can be performed using an idealized experiment. Indeed the instantaneous cloud radiative forcing (CRE) in both LW and SW domains at the TOA is defined by as :

$$
\begin{gathered}
C R E_{L W}=O L R_{c s}-O L R \\
C R E_{S W}=O S R_{c s}-O S R=I S R\left(\alpha_{c s}-\alpha\right)
\end{gathered}
$$

where $\mathrm{OLR}_{\mathrm{cs}}$ and $\alpha_{\mathrm{cs}}$ correspond respectively to OLR and albedo in clear sky conditions and ISR is the incoming solar radiation. Following Ramanathan et al. (1987), both total radiative quantities can be split in a part due to clear-sky situations and a part due to overcast situations and Eq. (1) can be rewritten as : 


$$
\begin{gathered}
C R E_{L W}=A_{c}\left(O L R_{c s}-O L R_{o}\right)=A_{c} O L R_{c s}-A_{o t h e r} O L R_{o t h e r}-A_{2 a} O L R_{2 a} \\
C R E_{S W}=A_{c} I S R\left(\alpha_{c s}-\alpha_{o}\right)=I S R\left(A_{c} \alpha_{c s}-A_{\text {other }} \alpha_{o t h e r}-A_{2 a} \alpha_{2 a}\right)
\end{gathered}
$$

where $A_{c}$ represents the cloud cover fraction and $O L R_{o}$ and $\alpha_{o}$ respectively the OLR and the albedo of the overcast region. The cloud cover $\mathrm{A}_{\mathrm{c}}$ has been further split according to the cloud cover of MCS 2a $\left(A_{2 a}\right)$ and the cloud cover of other cloud types $\left(A_{\text {other }}\right)$. All quantities involved in Eq. (2) change with location, date and time within the diurnal cycle. In addition, the third term in Eq. (2) depends also on the MCS life stage. This term can be computed from the previously built composites and from the TOOCAN outputs. TOOCAN algorithm provides at a 30-minute time step the fraction of individual class $2 \mathrm{a}$ MCS in a given $0.5^{\circ} \mathrm{x}$ $0.5^{\circ}$ grid box $\left(F_{f}\right.$, see section 3$)$ and then at this grid point scale, $A_{c}$ corresponds to $F_{f}$.

Sensitivity test can be performed by making different assumptions on $\operatorname{OLR}_{2 \mathrm{a}}$ and $\alpha_{2 \mathrm{a}}$. In the present study, we use a constant OLR and albedo values over the life cycle. They are computed as the mean over the ten life stages giving an equal weight to each life stage. The dependency with SZA is kept for $\alpha_{2 a}$, by computing this mean value for each SZA. The difference of the third term of Eq. (2) with or without assumption on radiative properties can be directly interpreted as an instantaneous change in CRE (Eq. (3)) since the first and second terms remain unchanged.

$$
\begin{aligned}
& \Delta C R E_{L W}=-A_{2 a} \Delta O L R_{2 a} \\
& \Delta C R E_{S W}=-A_{2 a} I S R \Delta \alpha_{2 a}
\end{aligned}
$$

The distribution of instantaneous anomalies in CRE resulting from the omission of the life cycle resolved radiative properties as a function of $F_{f}$ is shown in Figure 9 in order to display the individual increments that contribute to the total anomaly of CRE at a regional scale. This figure shows that the changes in CRE do not necessarily respond linearly with $F_{f}$ even if the mean increases. The spread is also larger for higher value of $F_{f}$. The mean values of OLR considered for the entire life cycle are $134.5 \mathrm{Wm}^{-2}$ and $136 \mathrm{Wm}^{-2}$ respectively for 

underestimation at the beginning and the end of the life cycle when the MCS are the smallest, and to an overestimation about the middle of the life cycle when the MCS are the largest. The inverse holds for albedo, which has a bell shape evolution with the life cycle. This effect is nevertheless aliased by the MCS varying area with the life cycle that exacerbates the underestimation (respectively overestimation) in LW (resp. SW) when the systems have a wide area (and occupying a large number of grid point with a high $\mathrm{F}_{\mathrm{f}}$ ). For $\mathrm{LW}$, the resulting uncertainty expressed as the variance of the true cycle versus the mean value reaches $8,6.0$, and 5.9 $\mathrm{Wm}^{-2}$ for Africa, South America and Pacific Ocean, respectively. For SW, the results vary also with the SZA and ranges from $\sim 4$ to $\sim 40 \mathrm{Wm}^{-2}$ for dawn and noon, respectively. These values are larger than the uncertainty in the flux estimations provided in Section 2a.

Omission of the evolution of radiative properties within the life cycle leads to an underestimation of CRE in the LW and an overestimation in the SW because this anomaly is a function of $F_{f}$. The obtained values are higher for larger $F_{f}$ and can be larger than $+/-10 \mathrm{Wm}^{-2}$. Distributions in the SW are relatively similar in the considered regions, with positive anomalies that can be higher than $10 \mathrm{Wm}^{-2}$. The LW contributions have more differences, with more spread over continental Africa for large $F_{f}$ with respect to Pacific. The net CRE anomaly for Continental Africa is dominated by the anomaly in the LW because of the late triggering of MCS as illustrated in Figure 8. In the South America region where MCS are triggered two to three hours earlier, both anomalies tend to compensate. This compensation effect is observed even stronger in the Pacific Ocean. However, the compensation effect may also be fortuitous as both errors have effects that compensate. It would not have occurred if different assumptions were made for this sensitivity test and points towards compensating errors that may induce small errors on radiative properties. In summary this sensitivity experiment has shown that neglecting the evolution of radiative properties with the life cycle led to 
uncertainty in radiative properties that may exceed the accuracy of flux estimates especially when the MCS have a wide area (and therefore occupy several grid points with high $\mathrm{F}_{\mathrm{f}}$ ). The occurrence within the diurnal cycle is of particular importance for balancing the effect in the SW and in the LW: error on MCS radiative properties are more easy to balance between SW and LW in oceanic regions where MCS spent more time in day light compared to continental

540 regions where MCS radiative properties are dominated by effect in the LW.

\section{Conclusion}

This paper explores the evolution of radiative properties throughout the MCS life cycle using TOA observations from the ScaRaB-3 radiometer onboard the Megha-Tropiques satellite. The data analysis is carried at the whole Tropics scale using five years of collocated

545 geostationary and ScaRaB-3 data. The MCS life cycle is documented using a tracking algorithm applied to geostationary data. Each time ScaRaB swath intercepts an MCS the life stage is stored as well as the TOA radiative properties measured at the scale of the MCS. This approach is used to build a composite view of the evolution of radiative properties over the MCS life cycle using the tracking as a framework. This study extends former ones (Futyan

550 and Del Genio 2007; Feng et al. 2011; Bouniol et al. 2016; Wall et al. 2018) focused on limited season and geographical areas.

Particular attention has been paid to the limitations resulting from sampling ability of the ScaRaB-3 radiometer. This step ensures that the isolated signal is well attributable to MCS anvil cloud. To do so we showed that only ScaRaB grid points filled at least at $70 \%$ by

555 a convective cloud and belonging to MCS larger than $610^{3} \mathrm{~km}^{2}$ should be considered. The wide swath of the ScaRaB only reduces the considered sample, without introducing a bias toward a particular population.

Composites are built at the tropical scale, and then separately for continent and ocean or according to particular geographical areas. All composites share common features, 
including a unique maximum in albedo and a unique minimum in OLR. However, amplitudes, minimum and maximum values of albedo and OLR and amplitude of the life cycle differ depending on the region. In particular continental MCS are brighter (in terms of albedo) and colder (in terms of OLR) in agreement with previous studies. The precessing orbit allows to distinguish the albedo values for each LST (or SZA) and if the shape of the evolution with the

565 life cycle is kept unchanged for a given LST the values are higher when SZA is small. The variations in albedo with SZA dominate the variations of albedo throughout the life cycle in response to the evolution of the microphysical properties within the anvils. Evolution in microphysical and macrophysical properties are directly responsible for changes in OLR. A first conclusion that can be drawn from this study is the absolute necessity of considering the

570 SZA when assessing cloud radiative properties in the SW because normalization by the incoming solar radiation does not remove this dependency, as highlighted by Rutan et al. (2014). In addition, Wall et al. (2020) raise the fact that the diurnal variations of radiative heating affect the anvil life cycle and that MCS triggering and developing during night time have different macrophysical and radiative properties compared to the one triggering and

575 developing during day time due to a different balance between shortwave and longwave heating.

These results highlight the subtle combination at play among occurrence, cloud area, radiative properties and phasing with diurnal cycle in the building of radiation budget at regional scale and further confirm the importance of this combination at the whole tropical scale. Our study indicates that uncertainty in the representation of life cycle related radiative properties may lead to anomalies in CRE larger than $10 \mathrm{Wm}^{-2}$ in absolute value, in particular when the systems are the largest (i.e. about the middle of their life cycle). These CRE anomalies may exceed the magnitude of the uncertainty in the current flux estimations, stressing the importance of accounting for the life cycle resolved systems properties in 
585 interpreting the radiative budget. The results also show significant regional variability that prompts cautionary use of local microphysical properties such as those obtained during fields campaigns at a more global scale.

\section{Acknowledgements}

This study benefited from the IPSL mesocenter ESPRI facility, which is supported by CNRS,

590 UPMC, Labex L-IPSL, CNES and Ecole Polytechnique. The authors acknowledge the CNES and CNRS support under the Megha-Tropiques program.

\section{Data availability statement}

Output of TOOCAN algorithm for the 2012 and 2016 period are publicly available. The dataset is identified with the DOI: $10.14768 / 20191112001.1$. More information can be found

595 at http://toocan.ipsl.fr. The ScaRaB-3 data can be downloaded. The ScaRab L2B are available in the ICARE data and service center with an Anonymous File Transfer Protocol: ftp://ftp.icare.univ-lille1.fr/SPACEBORNE/SCARAB/MT1 L2B-FLUX-

$\underline{\text { SCASL1A2 0.5deg.v2.01/ }}$ 


\section{References}

600 Bony, S., B. Stevens, D.M.W. Frierson, C. Jakob, M. Kageyama, R. Pincus, T.G. Shepherd, S.C. Sherwood, A.P. Siebesma, A.H. Sobel, M. Watanabe, M. and M.J. Webb, 2015: Clouds, circulation and climate sensitivity, Nat. Geosci., 8(4), 261-268. DOI:10.1038/ngeo2398.

Bony, S., B. Stevens, D. Coppin, T. Becker, K.A. Reed, A. Voigt and B. Medeiros, 2016 : Thermodynamic control of anvil cloud amount. PNAS, 113, 8927-8932. DOI : 10.1073/pnas.1601472113.

Bouniol, D., J. Delanoë, C. Duroure, A. Protat, V. Giraud, and G. Penide, 2010: Microphysical characterisation of West African MCS anvils, Q. J. R. Meteorol. Soc., 136(SUPPL. 1), 323-344. DOI:10.1002/qj.557.

610 Bouniol, D., R. Roca, T. Fiolleau and E. Poan, 2016: Macrophysical, microphysical, and radiative properties of tropical mesoscale convective systems along their life cycle. J. Climate, 29, 3353-3371. DOI:10.1175/JCLI-D-15-0551.1.

Del Genio, A. and W. Kovari W., 2002: Climatic Properties of Tropical Precipitating Convection under Varying Environmental Conditions. J. Clim., 15, 2597-2615, 2002.

615 Del Genio, A. D., Kovari, W., Yao, M. S. and J. Jonas, 2005: Cumulus microphysics and climate sensitivity, J. Clim., 18(13), 2376-2387, doi:10.1175/JCLI3413.1, 2005.

Del Genio, A., J. Wu and Y. Chen, 2012: Characteristics of Mesoscale Organization in WRF Simulations of Convection during TWP-ICE. J. Clim., 25, 5666-5688. DOI: 10.1175/JCLI-D-11-00422.1

620 Donner, L. J., C. J. Seman and R. S. Hemler, 2001: A cumulus parameterization including mass fluxes, convective vertical velocities, and mesoscale effects: Thermodynamic and hydrological aspects in a general circulation model. J. Climate, 14, 3444-3463.

Duvel, J. P., M. Viollier, P. Raberanto, R. Kandel, M. Haeffelin, L.A. Pakhomov, V.A. 
Golovko, J. Mueller, R. Stuhlmann and the international ScaRaB Scientific Working Group, 2001: The ScaRaB-resurs earth radiation budget dataset and first results. Bull. Am. Metereol. Soc. 82, 1397-1408. DOI: 10.1175/15200477(2001)082<1397:TSRERB>2.3.CO;2

Eitzen, Z.A., K.-M. Xu and T. Wong, 2009 : Cloud and Radiative Characteristics of Tropical Deep Convective Systems in Extended Cloud Objects from CERES Observations. J. Clim., 22, 5983-6000. DOI: 10.1175/2009JCLI3038.1

Elsaesser, G. S., Del Genio, A. D., Jiang, J. H. and Lier-Walqui, M. van, 2016 : An improved convective ice parameterization for the NASA GISS global climate model and impacts on cloud ice simulation, J. Clim., 30(1), 317-336. DOI:10.1175/JCLI-D-16-0346.1, 2017.

635 Feng, Z., X. Dong, B. Xi, C. Schumacher, P. Minnis and M. Khaiyer, 2011 : Top-ofatmosphere radiation budget of convective core/stratiform rain and anvil clouds from deep convective systems. J. Geophys. Res., 116, D23202. DOI:10.1029/2011JD016451.

Fiolleau T and R. Roca, 2013a. An algorithm for the detection and tracking of tropical mesoscale convective systems using infrared images from geostationary satellite. IEEE Transactions on Geoscience and Remote Sens., 51(7), 4302-4315. DOI: 10.1109/TGRS.2012.2227762.

Fiolleau T. and R. Roca, 2013b : Composite life cycle of tropical mesoscale convective systems from geostationary and low Earth orbit satellite observations: method and sampling considerations. Quart. J. Roy. Meteor. Soc., 139, 941-953. DOI:10.1002/qj.2174

Fiolleau, T., R. Roca, S. Cloché, D. Bouniol and P. Raberanto, 2020 : Homogenization of Geostationary Infrared Imager Channels for Cold Cloud Studies Using MeghaTropiques/ScaRaB. IEEE Transactions on Geoscience and Remote Sens., 58(9), 6609- 
6622. DOI: $\underline{10.1109 / T G R S .2020 .2978171}$

650 Futyan, J. M. and A.D. Del Genio, 2007: Deep Convective System Evolution over Africa and the Tropical Atlantic, J. Clim., 20, 5041-5060. DOI:10.1175/JCLI4297.1.

Gif, N., O. Chomette, and P. Raberanto, 2011: Co-location algorithms Geophysical data projection using pixel point spread function. ”Megha-Tropiques Tech. Memo., no. 2.

Hartmann, D. L., 2002: An important constraint on tropical cloud-climate feedback, Geophys. Res. Lett., 29(20), 10-13. DOI :10.1029/2002GL015835.

Hartmann, D. L., B. Gasparini, S.E. Berry and P.N Blossey, 2018: The Life Cycle and Net Radiative Effect of Tropical Anvil Clouds. J. Advances Model. Earth Syst., 10, 30123029. DOI:10.1029/2018MS001484.

Hohenegger, C. and B. Stevens, 2016: Coupled radiative convective equilibrium simulations with explicit and parameterized convection, J. Adv. Model. Earth Syst., 8(3), 14681482. DOI:10.1002/2016MS000666.

Houze Jr, R. A., 2004: Mesoscale Convective Systems. Rev. Geophys., 42(RG4003). DOI:10. 1029-2004RGOO0150.

Kandel, R., J.-L.Monge, M. Viollier, L.A. Pakhomov, V.I. Adasco, R.G. Reitenbach, R.G. Raschke and R. Stuhlmann, 1994 : The ScaRaB project: earth radiation budget observations from the meteor satellites. Adv. Space Res. 14, 47-54. DOI: 10.1016/02731177(94)90346-8

Kooperman, G. J., Pritchard, M. S., Burt, M. A., Branson, M. D. and Randall, D. A., 2016: Robust effects of cloud superparameterization on simulated daily rainfall intensity statistics across multiple versions of the Community Earth System Model. J. Adv. Model. Earth Syst., 8(1), 140-165. DOI:10.1002/2015MS000574.

Liou, K.N., 2002 : An introduction to Atmospheric Radiation. 2nd ed. International Geophysics Series, Vol. 84, Academic Press, 583pp. 
Loeb, N. G., S. Kato, K. Loukachine, N. Manalo-Smith, and D. R. Doelling, 2007: Angular distribution models for top-of-atmosphere radiative flux estimation from the Clouds and the Earth’s Radiant Energy System instrument on the Terra Satellite. Part II: Validation. J. Atmos. Ocean. Technol., 24, 564-584. DOI: 10.1175/JTECH1983.1.

Nesbitt, S. W., E. J. Zipser, and D. J. Cecil, 2000: A census of precipitation features in the Tropics using TRMM: Radar, ice scattering, and lightning observations. J. Climate, 13, 4087-4106.

Palmer, T. and B. Stevens, 2019: The scientific challenge of understanding and estimating climate change. PNAS, 116 (49) 24390-24395. DOI: 10.1073/pnas.1906691116.

Ramanathan, V., 1987 : The role of earth radiation budger studies in climate and general circulation research. J. Geophys. Res., 92, 4075-4095.

685 Ramanathan, V. and W. Collins, 1991 : Thermodynamic regulation of ocean warming by cirrus clouds deduced from observations of the 1987 El Niño. Nature, 351(6321), 2732. DOI : $10.1038 / 351027 \mathrm{a} 0$.

Roca, R. and V. Ramanathan, 2000 : Scale Dependence of Monsoonal Convective Systems over the Indian Ocean. J. Clim., 13(7), 1286-1298. DOI : 10.1175/15200442(2000)013<1286:sdomcs>2.0.co;2.

Roca, R., M. Viollier, L. Picon and M. Desbois, 2002: A multi satellite analysis of deep convection and its moist environment over the Indian Ocean during the winter monsoon. J. Geophys. Res, 107. DOI: 10.1029/2000JD000040.

Roca, R., S. Louvet, L. Picon and M. Desbois, 2005: A study of convective systems, water vapor and top of the atmosphere cloud radiative forcing over the Indian Ocean using INSAT-1B and ERBE data. Meteorology and Atmospheric Physics. DOI 10.1007/s00703-004-0098-3

Roca, R., H. Brogniez, P. Chambon, O. Chomette, S. Cloché., M.E. Gosset, J.-F. Mahfouf, P. 
Raberanto and N. Viltard, 2015 : The Megha-Tropiques mission, a review after three years in orbit. Frontiers in Earth Sci., 3, 1-14. DOI: 10.3389/feart.2015.00017

Roca, R., T. Fiolleau and D. Bouniol, 2017 : A Simple Model of the Life Cycle of Mesoscale Convective Systems Cloud Shield in the Tropics. J. Clim., 30, 4283-4298. DOI: 10.1175/JCLI-D-16-0556.1

Rutan, D., G.L. Smith and T. Wong, 2014 : Diurnal Variations of Albedo Retrieved from Earth Radiation Budget Experiment Measurements. J. Appl.Meteor. Climat., 53, 2747-2760. DOI : 10.1175/JAMC-D-13-01119.1.

Smith, G.L. and D.A. Rutan, 2003 : The diurnal cycle of Outgoing Longwave Radiation from Earth Radiation Budget Experiment Measurements. J. Atmos. Sci., 60, 1529-1542.

Sohn, B.-J., M.-J. Choi and J. Ryu, 2015 : Explaining darker deep convective cloud over the western Pacific than over tropical continental convective regions. Atmos. Meas. Tech., 8, 4573-4583.

Sokol, A. B. and D.L. Hartmann, D. L., 2020: Tropical anvil clouds: Radiative driving toward a preferred state. Journal of Geophysical Research: Atmospheres, 125, e2020JD033107. DOI: 10.1029/2020JD033107.

715 Trémas, T. L., Aznay, O. and O. Chomette, 2015: ScaRaB: first results of absolute and cross calibration, in Image and Signal Processing for Remote Sensing XXI, vol. 9643, p. 964304..

Vaillant de Guélis, T., H. Chepfer, V. Noël, R. Guzman, P. Dubuisson, D.M. Winker and S. Kato, 2017 : The link between outgoing longwave radiation and the altitude at which a spaceborne lidar beam is fully attenuated. Atmos. Meas. Tech., 10, 4659-4685. DOI : 10.5194/amt-10-4659-2017.

Viollier, M., C. Standfuss, O. Chomette and A. Quesney, 2009 : Top-of-Atmosphere Radiance-to-Flux Conversion in the SW Domain for the ScaRaB-3 Instrument on 
Megha-Tropiques. J. Atmos. Oceanic Technol., 26, 2161-2171. DOI: 10.1175/2009JTECHA1264.1

Wall, C.J., D. Hartmann, M.M. Thieman, W.L. Smith Jr and P. Minnis, 2018 : The Life Cycle of Anvil Clouds and the Top-of-Atmosphere Radiation Balance over the Tropical West Pacific. J. Clim., 31, 10059-10080 . DOI : 10.1175/JCLI-D-18-0154.1

Wall, C.J., J.R. Norris, B. Gasparini, W.L. Smith Jr., M.M. Thieman and O. Sourdeval, 2020: Observational Evidence that Radiative Heating Modifies the Life Cycle of Tropical Anvil Clouds. J. Climate, 33(20), 8621-8640. DOI: 10.1175/JCLI-D-20-0204.1

Webster, P. J. and G.L. Stephens: Tropical upper-tropospheric extended clouds: inferences from winter MONEX., J. Atmos. Sci., 37(7), 1521-1541. DOI:10.1175/1520-046937.7.1521, 1980.

Wing, A. A., 2019: Self-Aggregation of Deep Convection and its Implications for Climate. Curr. Clim. Chang. Reports, 5(1), 1-11. DOI:10.1007/s40641-019-00120-3.

Xu, K.-M., T. Wong, B.A. Wiekicki, L. Parker and Z.A. Eitzen, 2005 : Statistical Analyses of Satellite Cloud Object Data from CERES. Part I : Methodology and Preliminary Results of the 1998 El Nino/2000 La Nina. J. Clim., 18, 2497-2514.

740 Yang, G.-Y. and J. Slingo, 2001 : The diurnal cycle in the Tropics. Mon. Wea. Rev., 129, 784801.

Zelinka, M. D. and D.L. Hartmann, 2010: Why is longwave cloud feedback positive? J. Geophys. Res., 115(D16), 1-16. DOI:10.1029/2010JD013817.

Zelinka, M. D., Klein, S. A. and D.L. Hartmann, 2012: Computing and partitioning cloud feedbacks using cloud property histograms. Part II: Attribution to changes in cloud amount, altitude, and optical depth. J. Clim., 25(11), 3736-3754. DOI:10.1175/JCLI-D11-00249.1. 


\section{Figures}
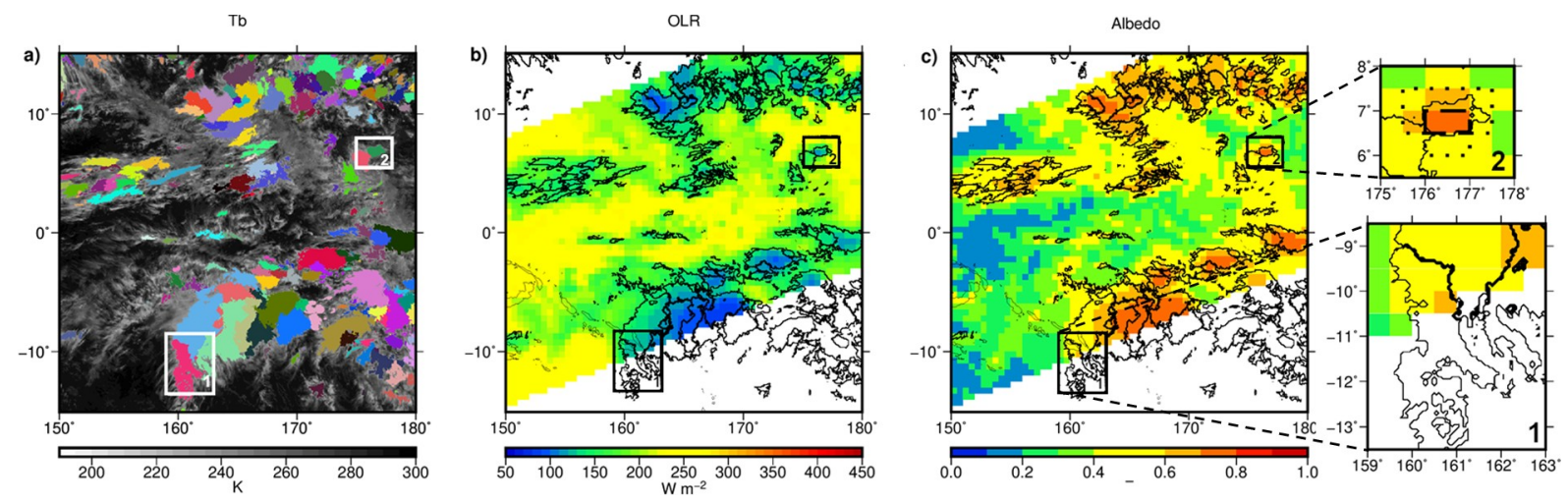

Figure 1 : Illustration of the composite process for cloud systems observed on 12 October 2015 at 4 UTC over the Pacific Ocean. a) Brightness temperature observed by Himawari identified by the TOOCAN algorithm (one color per object). b) OLR (color level) observed by ScaRaB-3 onboard Megha-Tropiques. c) Same as b) but for TOA albedo. Two zooms within this sample are also shown (location depicted by the two white rectangle in panel a and repeated in black in panels b) and c)) to illustrate particular sampling questions (see text). Black contours in panels $b$ ) and c) show the edges of the identified MCS. 
a)

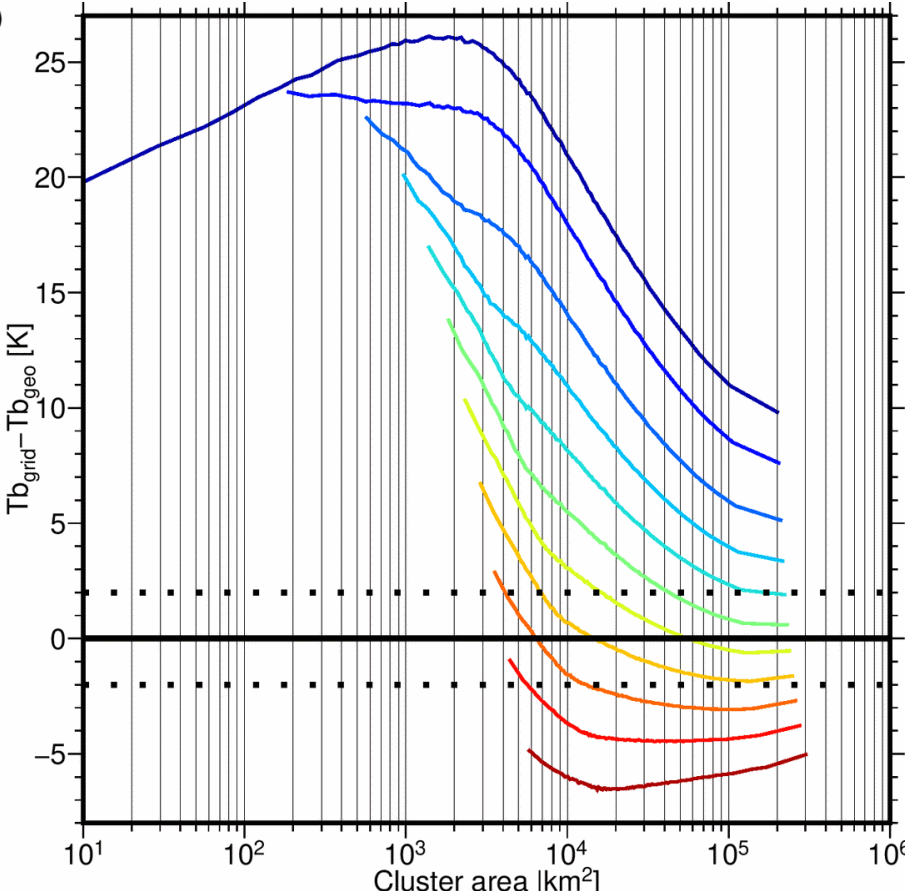

Nb_MCS $=2825748$ MCS 3725669

Noncs -4456729

$\mathrm{Nb}$ MCS $=5146870$

$\mathrm{Nb}$ MCS $=64853$

No_MCS $=715777$

No MCS $=8537904$

Nb_MCS=9370711

Nb MCS $=9997620$

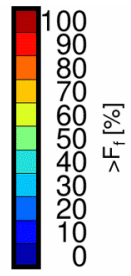

b)

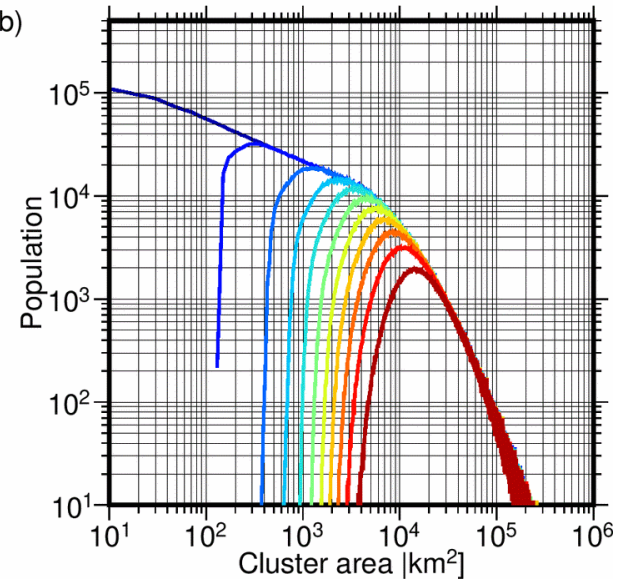

Figure 2 : (a) Difference in mean brightness temperature at the scale of MCS (in K) as a function of MCS area (in $\left.\mathrm{km}^{2}\right)$ computed from the full geostationary spatial resolution ( $\left.T \mathrm{~b}_{\text {geo }}\right)$ and from the ScaRaB resolution (Tb grid) considering different $F_{f}$ (in color). The numbers on the right hand side of panel a) show the number of MCS considered in the comparison. (b) Population of MCS as function of the MCS area for the different filling threshold. 

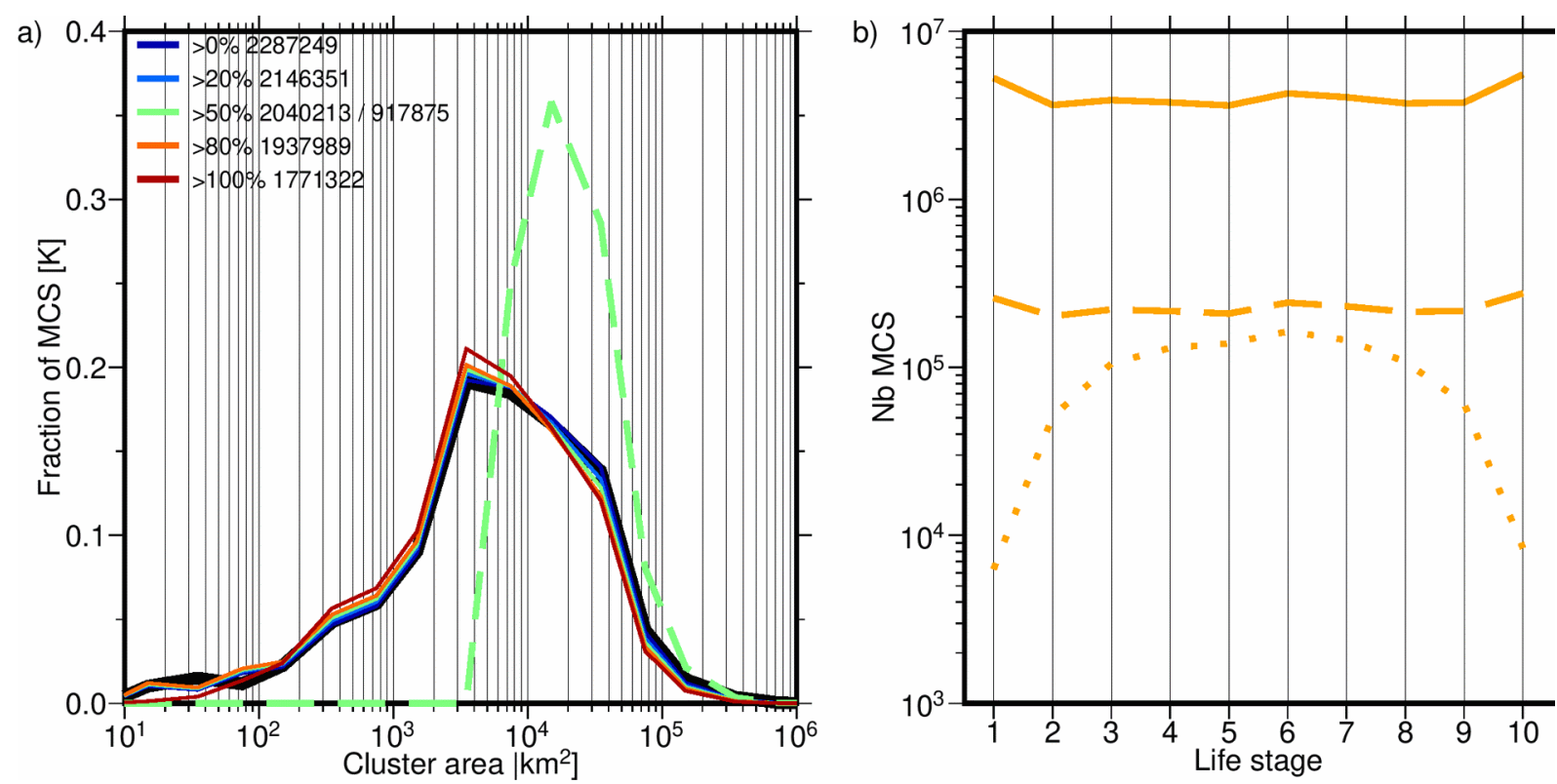

Figure 3 : (a) MCS area distribution independent of $F_{f}$ and with a minimum $F_{f}$ of $70 \%$ and a minimum area of $610^{3} \mathrm{~km}^{2}$ (dashed lines). The black line shows the distribution obtained from the TOOCAN data base at the scale of the whole Tropics, the color lines show the distributions considering the ScaRaB orbit and swath assuming different thresholds of MCS partial sampling. The number on the left hand side are the total number of MCS used to compute the distributions for the different swath-MCS intersections. The second number for a $50 \%$ intersection corresponds to the number of the MCS that can be considered for composite building assuming a $70 \% F_{f}$ and the minimum sampling area. (b) Number of MCS tracked by TOOCAN at the scale of the whole Tropics (solid line), sampled by ScaRaB, even partially (dashed line) and at least $50 \%$ sampled by ScaRaB, with a MCS grid filling of $70 \%$ and a minimum area of $610^{3} \mathrm{~km}^{2}$ (dotted line). 

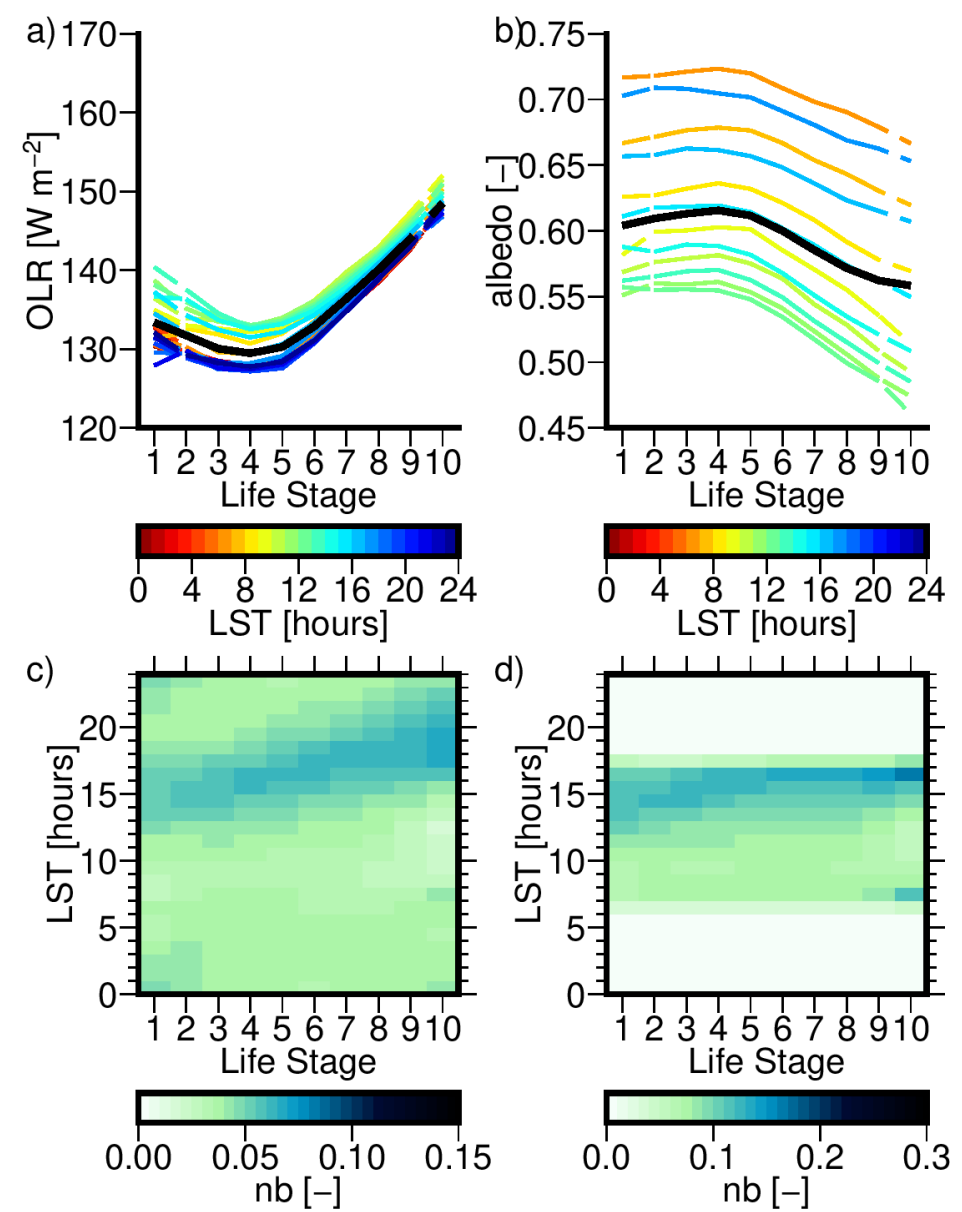

Figure 4 : Mean composite (black bold line) of (a) OLR in $\mathrm{Wm}^{-2}$ and (b) albedo as a function of the life stage at the scale of the whole tropical belt for MCS tracked between 2012 and 2016 by TOOCAN. Different colors show the mean composites according to different local solar times. Panels (c) and (d) show the fraction of MCS sampled at each LST for each life stage, where each column is normalized by the number of MCS observed in a given life stage. 

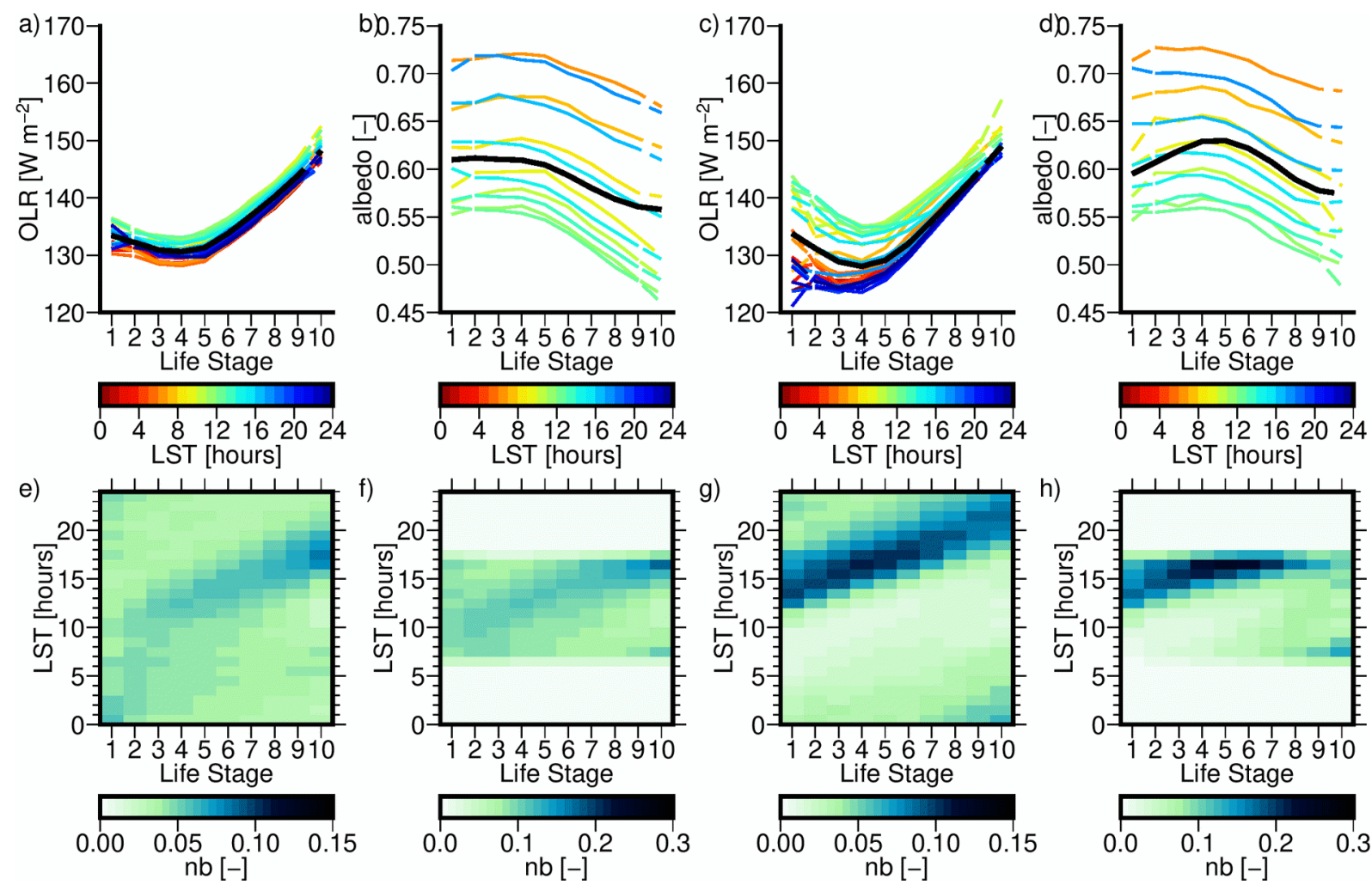

Figure 5 : Same as Figure 4 for oceanic MCS ( $a, b, e, f)$ and for continental MCS $(c, d, g, h)$. 

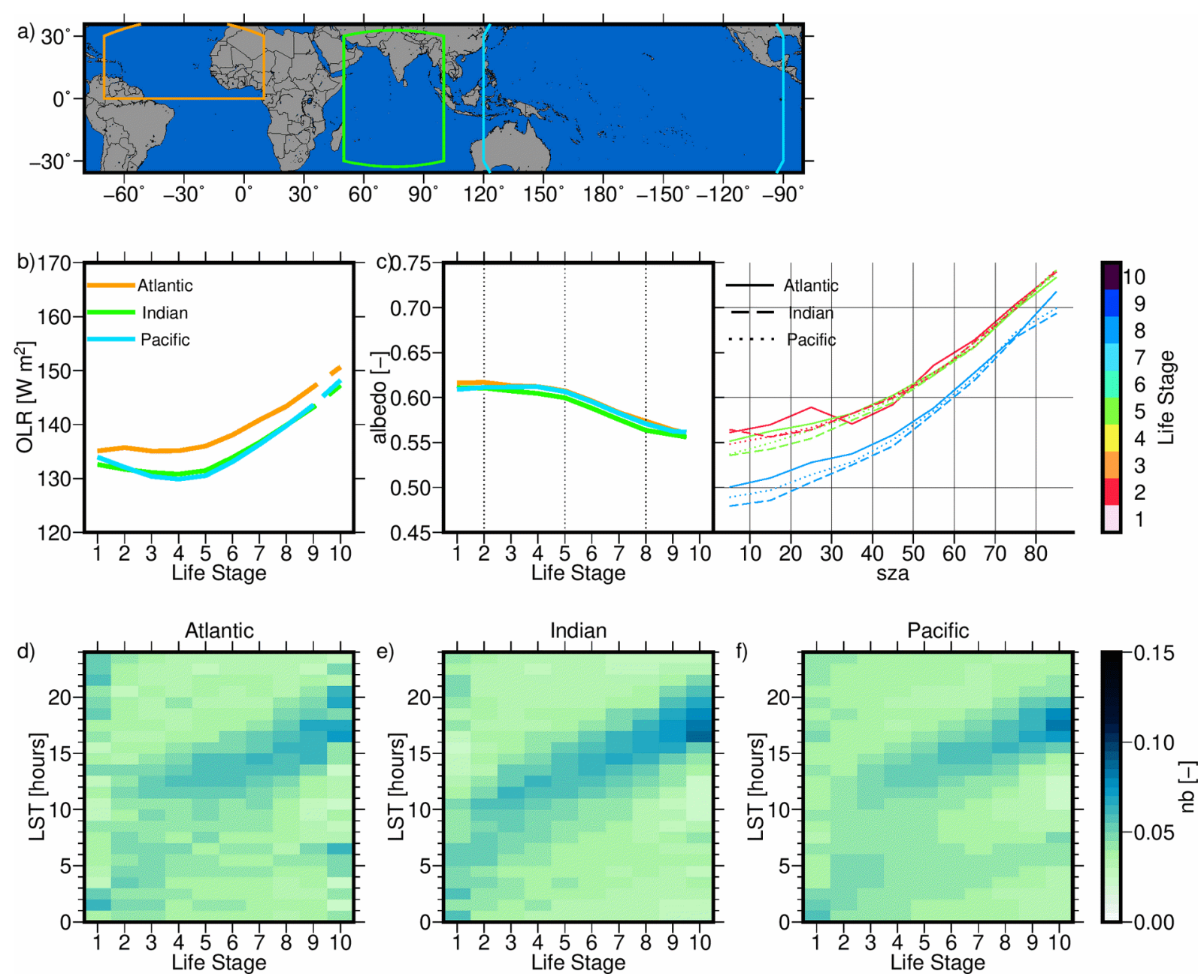

Figure 6 : Comparison of OLR and albedo over the MCS life cycle for three oceanic domains shown in (a). (b) Mean OLR as a function of life stage. (c) Mean albedo as a function of life stage and evolution of albedo with the solar zenith angle for three life stages 2, 5 and 8. ( $d$ - $f$ ) Distribution of MCS as a function of LST for each life stage for Atlantic, Indian and Pacific domains respectively. 

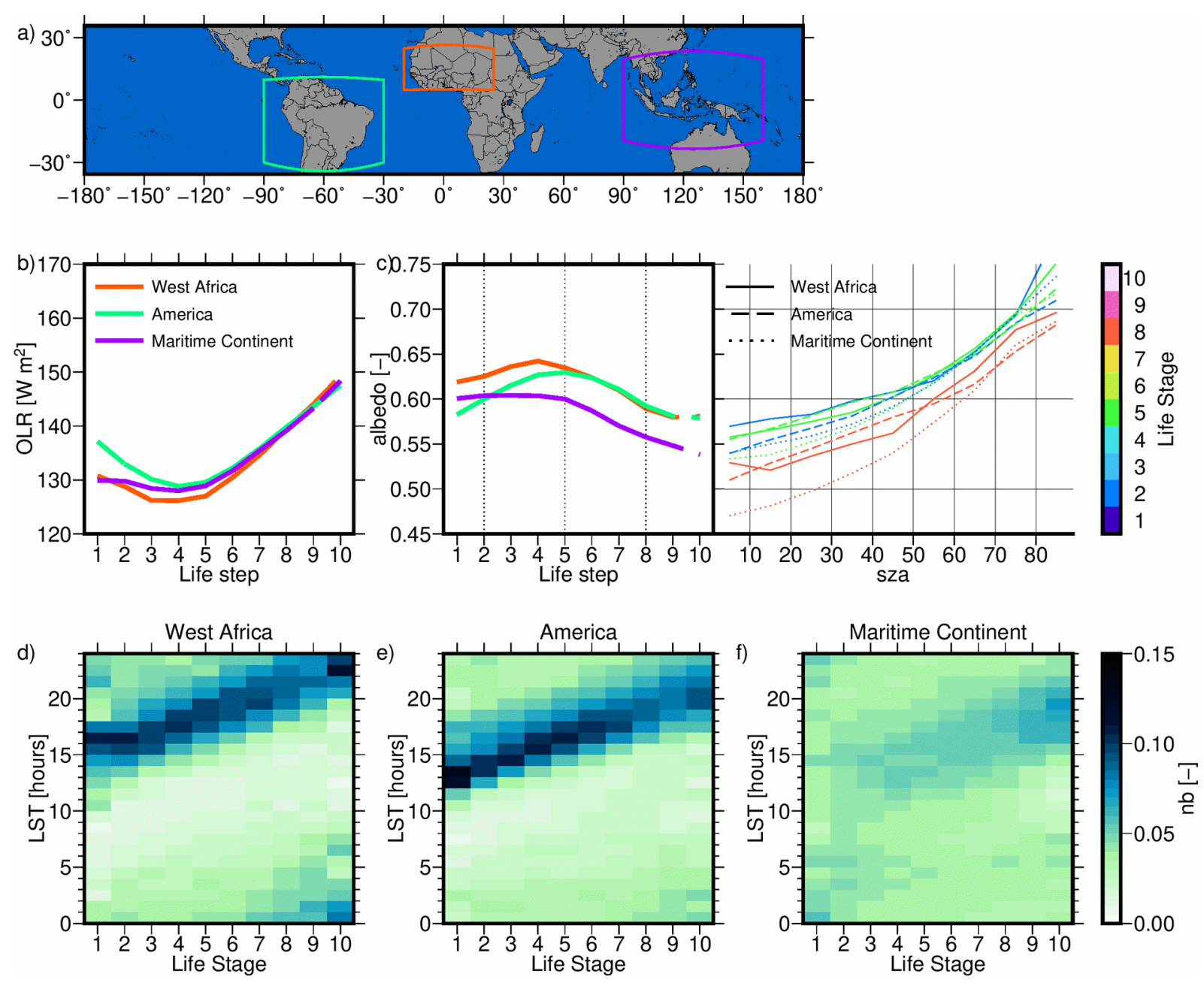

Figure 7 : Same as Figure 6 for continental MCS sampled in West Africa, South America and Maritime Continent. 

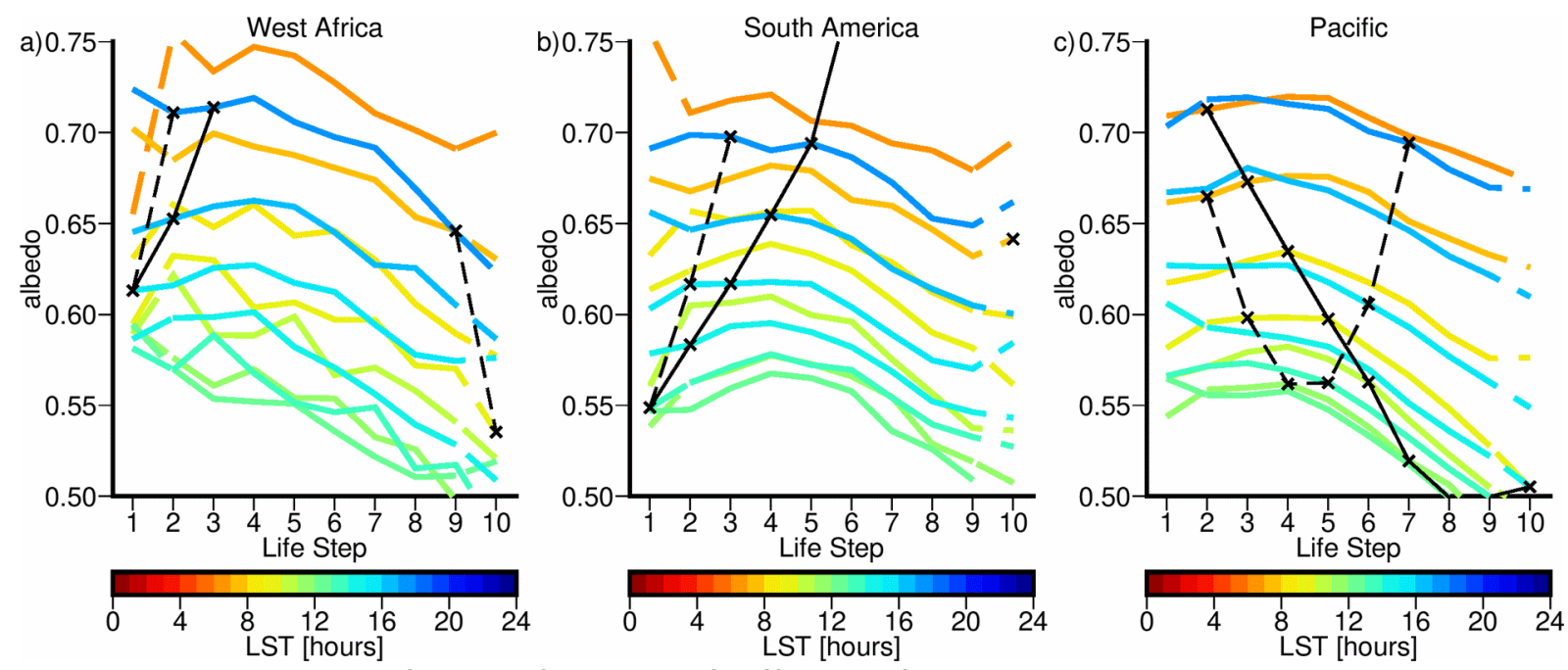

Figure 8 : Simulated life cycle for MCS of different life time durations: 10 hours (solid black line) and 20 hours (dashed black line) for typical times of triggering (a) 1500 LST in West Africa (b) 1300 LST in South America and (c) 0700 LST in the Pacific Ocean. Colored lines show the composites of albedo for all the observed MCS according to the LST (color scale). 

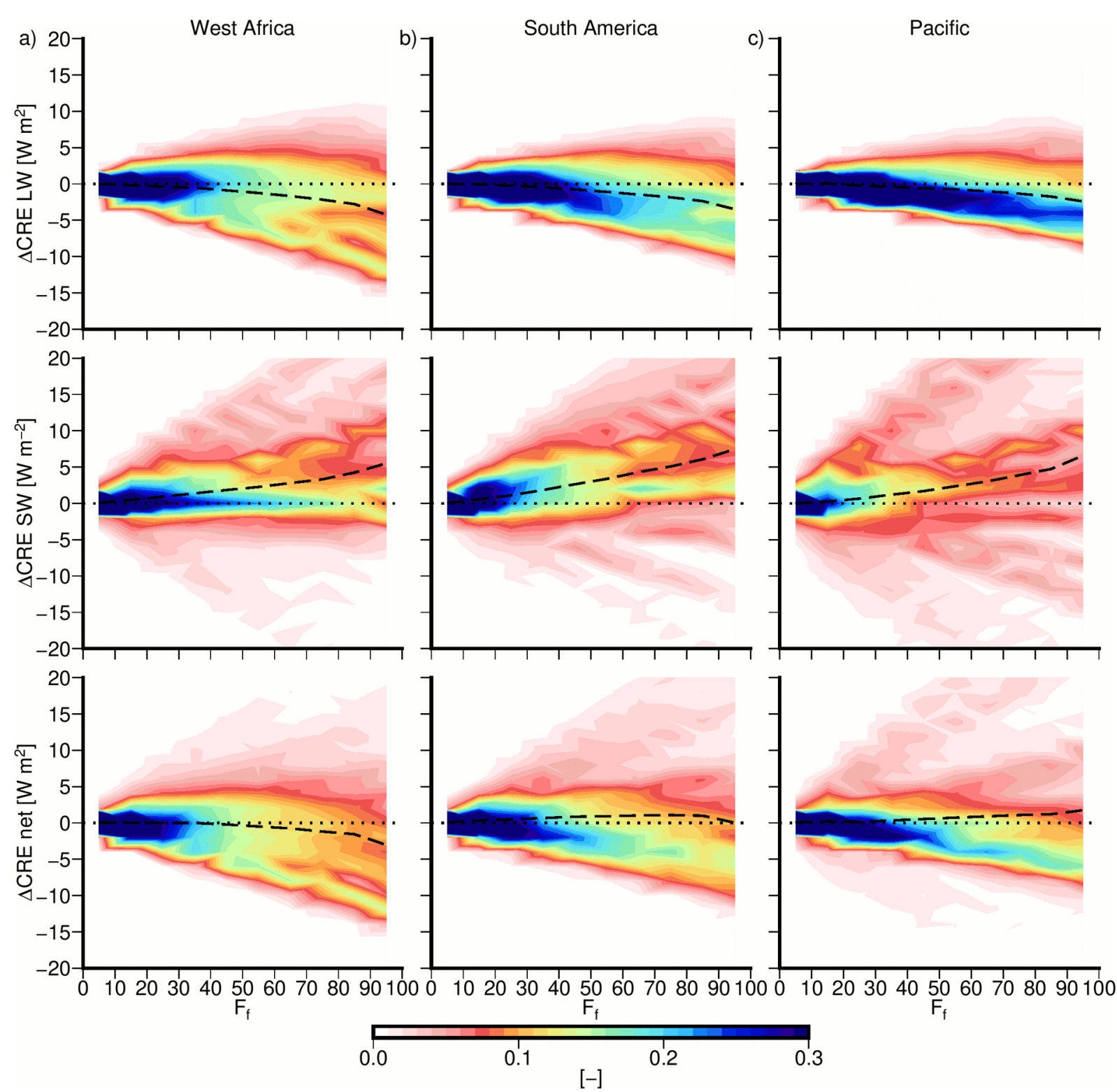

Figure 9: Distribution of anomalies in CRE resulting from the omission of the evolution of radiative properties with the life cycle as a function of the grid point filling (the distribution being normalized for each $F_{f}$ bin) for (a) Continental Africa (b) South America and (c) Pacific Ocean. For each region the anomalies in $L W, S W$, and the net radiation are shown. Dashed line show the mean anomaly in CRE as a function of $F_{f}$ 